\title{
EDITORIAL
}

\section{Emotional and psychological trauma in refugees arriving in Germany in 2015}

\author{
Molecular Psychiatry (2015) 20, 1483-1484; doi:10.1038/ \\ mp.2015.164; published online 27 October 2015
}

In the current year, 2015, Germany is experiencing the greatest influx of refugees since World War II. The German government is expecting $\sim 1$ million war refugees from Syria, Iraq, Eritrea and other countries to arrive this year. People who have had to flee their homelands because of war, torture and forced migration are being housed in provisional tent camps and converted sports halls in several German cities, including Dresden; these facilities are being managed by the German Red Cross for an indefinite time. In Dresden, medical care has been available on the premises in the framework of consultations by volunteer medical personnel since 27 July. On the basis of the increasing mental health needs of 1700 refugees, medical care was extended to include $6 \mathrm{~h}$ per week of psychiatric care as of 10 August 2015. The first 2 weeks of psychiatric care yielded the preliminary demographic data listed in Table 1.

Children and youths under 18 years of age arriving in Germany unaccompanied by a reference person are among the individuals most in need of protection. ${ }^{1,2}$ This particularly vulnerable group presumably has the greatest need for psychiatric attention. They typically have had no previous psychiatric evaluation. The local

Table 1. Early demographic data from a sample of psychiatric evaluations of refugees in Dresden, Germany, in $2015(N=23)$

\begin{tabular}{|c|c|c|}
\hline Characteristic & $\mathrm{n}$ & Percentage \\
\hline \multicolumn{3}{|l|}{ Age } \\
\hline Mean: 32.09 years; range: $17-48$ years & 22 & \\
\hline NA & 1 & \\
\hline \multicolumn{3}{|l|}{ Gender } \\
\hline Male & 17 & \\
\hline Female & 4 & \\
\hline NA & 2 & \\
\hline \multicolumn{3}{|l|}{ Diagnosis (ICD-10) } \\
\hline F43.1 & 10 & 43.5 \\
\hline F43.2 & 3 & 13.0 \\
\hline F20 & 1 & 4.3 \\
\hline F62 & 3 & 13.0 \\
\hline No diagnosis & 6 & 26.1 \\
\hline \multicolumn{3}{|l|}{ Life events } \\
\hline Multiple (including war, torture and escape) & 13 & 56.5 \\
\hline War+torture & 3 & 13.0 \\
\hline NA & 7 & 30.4 \\
\hline \multicolumn{3}{|l|}{ Neuroleptics } \\
\hline Prescribed & 10 & 43.5 \\
\hline Not prescribed & 11 & 47.8 \\
\hline NA & 2 & 8.7 \\
\hline \multicolumn{3}{|c|}{$\begin{array}{l}\text { Abbreviations: F43.1, post-traumatic stress disorder; F43.2, adjustment } \\
\text { disorders; F20, schizophrenia; F62, enduring personality changes not } \\
\text { attributable to brain damage and disease; ICD-10, International Classifica- } \\
\text { tion of Diseases, tenth edition; NA, not available. }\end{array}$} \\
\hline
\end{tabular}

youth welfare service (Jugendamt) is responsible for taking care of young refugees, who comprise $\sim 6 \%$ of total refugees and are housed in initial admission facilities. ${ }^{2}$ Certain traumatic life events have been experienced specifically by children, for example, separation from parents, forced recruitment as child soldiers or having been victims of child trafficking.

Psychiatric care of refugees has posed challenges right from the beginning, particularly the lack of interpreters and of languagespecific psychometric measuring instruments, as well as unsuitable premises for collecting psychiatric clinical data. Furthermore, the general living conditions of the refugees are not acceptable by any medical standards: inappropriate nutrition, lack of temperature regulation (heating/cooling) in the accommodations and deficient hygiene. Hostile and ostracizing utterances from local inhabitants gathering in front of the camps constitute an additional burden for the refugees. Even though they may not understand the statements because of a language barrier, they get the gist via the tone and volume of the voices, quite clearly grasping that local antagonists are demanding their immediate removal.

As can be seen in Table 1, the patients we have assessed so far have anxiety-related symptoms (criteria B-E, Diagnostic and Statistical Manual of Mental Disorders, fifth edition; DSM-V), including unrest, sleeping difficulties and flashbacks, which, in conjunction with the recently experienced events of war, forced migration and torture (criterion A 'stressor,' DSM-V), lead to the diagnosis of post-traumatic stress disorder (PTSD). As epidemiological data show, $50 \%$ of the individuals who became victims of war, forced migration and torture meet diagnostic criteria for PTSD. ${ }^{3,4}$ Patients with PTSD exhibit altered hypothalamus pituitary adrenal (HPA) axis activity. ${ }^{5}$ In addition, there are data supporting dysfunction of stress hormones in PTSD, with the possibility of intergenerational transmission for three generations. ${ }^{6,7}$

Stress and HPA axis dysregulation are elements of the pathophysiology of several disorders, including depression and Cushing's and Addison's disease. For an initial evaluation of HPA activity, single blood samples for the determination of adrenocorticotropin hormone and cortisol levels are commonly used, followed by further diagnostic tests such as those for midnight saliva cortisol concentrations and 24-h excretion of cortisol in the urine, as well as several additional functional tests, such as the corticotropin-releasing hormone-dexamethasone suppression test. $^{8-10}$ However, because ultradian and circadian variability make it difficult to evaluate the long-term activity state of the HPA axis, it would be highly desirable to have a biomarker of long-term HPA function, comparable to the $\mathrm{HbA1c}$ value in diabetes mellitus. ${ }^{11}$ Even with the limitation of current methods, it has already been shown that with growing age, as well as with depression or in PTSD, the HPA axis may be subject to a 'load factor' whereby greater HPA activity in old age is accompanied by an increase in physical capacity. ${ }^{12-15}$

Chronic changes in endogenous glucocorticoid production are typically a result of prolonged stress exposure. Patients with depression, generalized anxiety disorders or PTSD may exhibit disrupted HPA axis activity. ${ }^{16,17}$ Continuous activation of the HPA with chronically elevated cortisol concentrations may also result in downregulation of the glucocorticoid receptor or the corticotropin-releasing hormone system, as well as in telomere 
erosion. $^{18-20}$ Epigenetic inactivation mechanisms have been described for the glucocorticoid receptor gene, ${ }^{21}$ and it has been speculated that chronic emotional or psychological stress or sustained athletic activity may result in reduced responsiveness of the cortisol receptor and increased resistance to stress, potentially associated with longevity. 22

We previously showed in healthy students that physical activity and burdensome life events in the previous 3 months lead to an elevation of long-term steroids in hair. ${ }^{23}$

The language barrier in the adult refugees, as discussed above, and the complex histories and needs of underage refugees represent enormous challenges for diagnosis and treatment implementation. Even though all refugees experience trauma and stress, some are more vulnerable to develop mental illness than others in that context. Given the reality of limited resources, mental health care should be particularly focused on those who are more likely to develop PTSD, major depression or other psychiatric disorders. That would be greatly facilitated if we had reliable markers for those disorders. We hope that research leading to the identification and validation of new biomarkers will in the not-too-distant future facilitate the diagnosis of PTSD, depression and other disorders, and the assessment of treatment response. This is of considerable clinical relevance, as mass migration, war and trauma continue to generate increasing numbers of displaced refugees the world over.

\section{CONFLICT OF INTEREST}

The authors declare no conflict of interest

E Ullmann ${ }^{1,2}$, A Barthel ${ }^{1,3}$, S Taché ${ }^{4}$, A Bornstein ${ }^{1}$, J Licinio ${ }^{5}$ and SR Bornstein ${ }^{1,6}$

${ }^{1}$ Department of Medicine, University of Dresden, Dresden, Germany;

${ }^{2}$ Center of Developmental Pediatrics, City Hospital Dresden, Dresden,

Germany;

${ }^{3}$ Endokrinologikum Ruhr, Bochum, Germany;

${ }^{4}$ German Red Cross, Dresden, Germany;

${ }^{5}$ Mind and Brain Theme, South Australian Health and Medical Research Institute, Flinders University, Adelaide, Australia and ${ }^{6}$ Endocrinology and Diabetes, Division of Diabetes \& Nutritional Sciences, Rayne Institute, Denmark Hill Campus, Faculty of Life Sciences \& Medicine, Kings College London, London, UK E-mail: enrico.ullmann@uniklinikum-dresden.de

\section{REFERENCES}

1 German Bundestag. Situation of unaccompanied underage refugees. Bundestag Printed Paper 18/5564, 2015.
2 City of Chemnitz/Saxony. Information I-044/2015, 2015.

3 Forbes $\mathrm{D}$ et al. Australian guidelines for the treatment of adults with acute stress disorder and post-traumatic stress disorder. Aust NZ J Psychiatry 2015; 41: 637-648.

4 Kessler RC, Sonnega A, Bromet E, Hughes M, Nelson CB. Posttraumatic stress disorder in the National Comorbidity Survey. Arch Gen Psychiatry 1995; 52: 1048-1060

5 Meewisse ML, Reitsma JB, de Vries GJ, Gersons BP, Olff M. Cortisol and posttraumatic stress disorder in adults: systematic review and meta-analysis. $\mathrm{Br} J$ Psychiatry 2007; 191: 387-392.

6 Yehuda $\mathrm{R}$ et al. Low cortisol and risk for PTSD in adult offspring of holocaust survivors. Am J Psychiatry 2000; 157: 1252-1259.

7 Ullmann E et al. Increased rate of depression and psychosomatic symptoms in Jewish migrants from the post-Soviet-Union to Germany in the 3rd generation after the Shoa. Transl Psychiatry 2013; 3: e241.

8 Lovas K, Husebye ES. Addison's disease. Lancet 2005; 365: 2058-2061.

9 Merke DP, Bornstein SR. Congenital adrenal hyperplasia. Lancet 2005; 365: 2125-2136.

10 Newell-Price J, Bertagna X, Grossman AB, Nieman LK. Cushing's syndrome. Lancet 2006; 367: 1605-1617.

11 Bolinder J, Ungerstedt U, Arner P. Long-term continuous glucose monitoring with microdialysis in ambulatory insulin-dependent diabetic patients. Lancet 1993; 342: 1080-1085.

12 Belvederi Murri $M$ et al. HPA axis and aging in depression: systematic review and meta-analysis. Psychoneuroendocrinology 2014; 41: 46-62.

13 Gardner MP et al. Dysregulation of the hypothalamic pituitary adrenal (HPA) axis and physical performance at older ages: an individual participant meta-analysis. Psychoneuroendocrinology 2013; 38: 40-49.

14 Gardner MP et al. Diurnal cortisol patterns are associated with physical perfor mance in the Caerphilly Prospective Study. Int J Epidemiol 2011; 40: 1693-1702.

15 Morris MC, Compas BE, Garber J. Relations among posttraumatic stress disorder, comorbid major depression, and HPA function: a systematic review and metaanalysis. Clin Psychol Rev 2012; 32: 301-315.

16 Dettenborn $L$ et al. Introducing a novel method to assess cumulative steroid concentrations: increased hair cortisol concentrations over 6 months in medicated patients with depression. Stress 2012; 15: 348-353.

17 Steudte $S$ et al. Increased cortisol concentrations in hair of severely traumatized Ugandan individuals with PTSD. Psychoneuroendocrinology 2011; 36: 1193-1200.

18 Collip D et al. FKBP5 as a possible moderator of the psychosis-inducing effects of childhood trauma. Br J Psychiatry 2013; 202: 261-268.

19 Rogers J et al. CRHR1 genotypes, neural circuits and the diathesis for anxiety and depression. Mol Psychiatry 2013; 18: 700-707.

20 Shalev I et al. Exposure to violence during childhood is associated with telomere erosion from 5 to 10 years of age: a longitudinal study. Mol Psychiatry 2013; 18 576-581.

21 Klengel T et al. Allele-specific FKBP5 DNA demethylation mediates gene-child hood trauma interactions. Nat Neurosci 2013; 16: 33-41.

22 Terry DF, Sebastiani P, Andersen SL, Perls TT. Disentangling the roles of disability and morbidity in survival to exceptional old age. Arch Intern Med 2008; 168: 277-283.

23 Ullmann E et al. Pilot study of adrenal steroid hormones in the hair as an indicator of chronic mental and physical stress (Submitted). 